\title{
Identification of the nuclear matrix and chromosome scaffold in dinoflagellate Crypthecodinium cohnii ${ }^{1}$
}

CAI Shutao*, Congmei ZENG**, Jingyan LI** and ZHONGHE ZHAI*2

* Department of Biology, Beijing University, Beijing 100871, China.

* * Kunming Institute of Zoology, Academia Sinica, Kunming 650107, China.

\begin{abstract}
Dinoflagellate is one of the primitive eukaryotes, whose nucleus may represent one of the transition stages from prokaryotic nucleoid to typical eukaryotic nucleus. Using selective extraction together with embeddment-free section and whole mount electron microscopy, a delicate nuclear matrix filament network was shown, for the first time, in dinoflagellate Crypthecodinium cohnii nucleus. Chromosome residues are connected with nuclear matrix filaments to form a complete network spreading over the nucleus. Moreover, we demonstrated that the dinoflagellate chromosome retains a protein scaffold after the depletion of DNA and soluble proteins. This scaffold preserves the characteristic morphology of the chromosome. Two dimensional electrophoreses indicated that the nuclear matrix and chromosome scaffold are mainly composed of acidic proteins. Our results demonstrated that a framework similar to the nuclear matrix and chromosome scaffold in mammalian cells appears in this primitive eukaryote,suggesting that these structures may have been originated from the early stages of eukaryote evolution.
\end{abstract}

Key words: nuclear matrix, chromosome scaffold, dinoflagellate, Crypthecodinium cohnii.

\section{INTRODUCTION}

Most of researches on nuclear matrix and chromosome scaffold were concentrated on higher eukaryotes, especially on mammalian cells. For the investigation of the devel-

1. Part of the work was first published in Chinese in Acta Biologie Experimentalis Sinica 1991.24(1)33-44.

2. Author for correspondence. 
opment and evolution of nuclear matrix and chromosome scaffold in eukaryote, lower eukaryotes are ideal experimental models. Dinoflagellate is one of the primitive eukaryotes and its nucleus possesses numerous unusual nuclear characteristics, such as little to no histone associated with the DNA[1,2], lack of nucleosomes [3,4], the presence of large amounts of the base 5-hydroxymethyluracil [5,6] ,and unusual mitosis [7-10]. In view of these unusual features, Dodge[11] introduced the term mesokaryote to distinguish dinoflagellates from eukaryotes. On the other hand, the dinoflagellates have similarities to classic eukaryotes. They possess a well defined nucleus, nucleolus and chromosomes, and a total DNA content and sequence complexity similar to advanced eukaryotes. The dinoflagellates cytoplasm contains all those organelles characteristic of eukaryotic cells. It is generally agreed that the dinoflagellates are true eukaryotes, but may belong to one of the older lineage of eukaryotes and their nuclei may represent the transition stages from prokaryotic nucleoid to typical eukaryotic nucleus.

Compared with the detailed knowledge of the DNA on molecular level, little is yet known of its organization in the nucleus. The existence of a nuclear matrix or nucleoskeleton in higher eukaryote has been demonstrated in numerous studies [12-18]. Its isolation and characterization stimulated the investigation of nuclear structure and function in eukaryotic cells. The association of nuclear matrix with DNA replication, RNA transcription and processing, virus reproduction and other life activities soon becomes an exploding area of cell biology research[19]. Meanwhile, Laemmli and his colleagues showed that, after the histones and most of the nonhistone proteins were gently removed from HeLa metaphase chromosome, there existed a nonhistone protein scaffold that retained the size and shape of intact chromosome, and to which the DNA was attached, predominantly forming 1oops[20-22]. Also, the protein scaffold could be isolated independently of the DNA by treating HeLa chromosomes with micrococcal nuclease before removing the histones[23]. Thus, chromosome scaffold was considered to be an important structural component of the highly organized chromosome.

Among all kinds of eukaryote chromosomes, the chromosomes of dinoflagellates are most similar to prokaryote chromatin structure, the nucleoid. The dinoflagellates contain no obvious histone - like proteins and only slight amounts of basic chromosomal proteins. Nuclease digestion experiments have failed to reveal a nucleosomal or other short- range DNA packing arrangement[4]. Transmission electron microscopic observations of dinoflagellate chromosomes in thin section consistently revealed that the diameter of fibrils similar to that of protein-free DNA [24], and chromosomes were highly organized. The ultrastructure of dinoflagellate chromosome has been studied extensively for over a quarter of a century and for explaining how the DNA organized into a highly condensed chromosome, several distinctly contradictory models were proposed [9,25-30]. Some authors suggested that the chromosome contains a backbone[25] or a central core[30] to support and maintain the loops of DNA that make up the chromonema. Such hypotheses have not been confirmed yet.

In the present study, we isolated and examined the nuclear matrix and chromosome scaffold in typical dinoflagellate, Crypthecodinium cohnii. The experimental results demonstrated the existence of such delicate structures in dinoflagellate cells. 


\section{MATERIALS AND METHODS}

\section{Cell culture}

Crypthecodinium cohnii cells were obtained from Center of Algae Culture, Teaxs A \& M University, and grown at $2628^{\circ} \mathrm{C}$ in $\mathrm{E}_{6}$ medium.

\section{Epon embeddment sections}

The cells were fixed in $2.5 \%$ glutaraldehyde for $2 \mathrm{~h}$ at $4^{\circ} \mathrm{C}$ and postfixed in $1 \% \mathrm{OsO}_{4}$ in $\mathrm{PBS}$ for $2 \mathrm{~h}$ at $4^{\circ} \mathrm{C}$. After washing they were dehydrated through a series of ethanol steps and embedded in Epon 812(Serva). Thin section (500 $700 \AA$ ) were cut, stained with uranyl acetate and lead citrate and viewed with JEM 100 CX electron microscope.

\section{Cell Fractionation}

Fractionation steps were essentially as described by Fey et al [18]with some modifications. Crypthecodinium cohnii cells grown by suspension culture were treated at $4^{\circ} \mathrm{C}$ according to the following procedures. The cells were extracted in cytoskeleton buffer (CSK: $100 \mathrm{~m} M \mathrm{KCl}, 300 \mathrm{~m} M$ sucrose, $100 \mathrm{~m} M$ PIPES, pH 6.8, $3 \mathrm{~m} M \mathrm{MgCl}_{2}, 1.2 \mathrm{~m} M$ phenylmethylsulfonyl fluoride, $0.5 \%$ Triton X 100) for $5 \mathrm{~min}$. The cytoskeleton frameworks were separated from soluble proteins by centrifugation at $600 \mathrm{~g}$ for $5 \mathrm{~min}$. The cytoskeleton framework pellets were extracted in RSB Magik buffer (42.5 mM Tris $\mathrm{HCl}, \mathrm{pH}$ 8. 3, $8.5 \mathrm{~m} M \mathrm{NaCl}$, $2.6 \mathrm{~m} M \mathrm{MgCl}_{2}, 1.2 \mathrm{~m} M$ phenylmethylsulfonyl fluoride, $1 \%$ (vol/vol) Tween 40, 0.5\% sodium desoxycholate) for $5 \mathrm{~min}$ and pelleted as before. This step stripped away the microtubules and microfilaments leaving in the pellet nuclei. The remnant pellet was resuspended in digestion buffer (the same as CSK buffer except used $50 \mathrm{mM} \mathrm{NaCl}$ instead of $\mathrm{KCl}$ ), and added $400 \mu \mathrm{g} / \mathrm{ml}$ bovine pancreatic DNase I (Sigma) and digestion proceeded for $40 \mathrm{~min}$ at $20^{\circ} \mathrm{C}$. Ammonium sulfate was added to a final concentration of $0.25 \mathrm{M}$ and incubation continued for $5 \mathrm{~min}$. The sample was then centrifuged at $1000 \mathrm{~g}$ for $5 \mathrm{~min}$. This step removed the chromatin fraction and left behind the RNP containing nuclear matrix fraction. RNA and associated proteins were released from nuclear matrix after digestion with $100 \mu \mathrm{g} / \mathrm{ml} \mathrm{RNase} \mathrm{A(Sigma)} \mathrm{in} \mathrm{CSK} \mathrm{buffer} \mathrm{for} 10 \mathrm{~min}$ at $20^{\circ} \mathrm{C}$ to give the RNP depleted nuclear matrix pellet.

\section{Chromosome scaffold preparation}

The dinoflagellate chromosomes were isolated according to the method of Rizzo and Noodén[1]. Chromosome scaffold were prepared essentially according to the description of Adolph et a1 [23] in HeLa cells with some modifications. We used the following procedure to prepare the chromosome scaffolds of C. cohnii cells: the isolated chromosomes were digested in a mixture of $200 \mu \mathrm{g} / \mathrm{ml}$ DNase I, $10 \mathrm{~m} M$ PIPES, pH 6.8, $50 \mathrm{~m} M \mathrm{NaCl}, 50 \mathrm{~m} M \mathrm{KCl}, 300 \mathrm{~m} M$ sucrose, $3 \mathrm{~m} M \mathrm{MgCl}_{2}, 1 \mathrm{~m} M$ EGTA and $1.2 \mathrm{~m} M$ phenylmethylsulfonyl fluoride at $20^{\circ} \mathrm{C}$ for $20 \mathrm{~min}$. Then, the chromosomes were extracted with a mixture containing $2 \mathrm{mg} / \mathrm{ml}$ dextran sulfate, $0.2 \mathrm{mg} / \mathrm{ml}$ heparin, $10 \mathrm{~m} M$ Tris, $\mathrm{pH}$ 9.0, $10 \mathrm{~m} M$ EDTA, 0. 1\% NP 40 and $1.2 \mathrm{~m} M$ phenylmethylsulfonyl fluoride, at $4^{\circ} \mathrm{C}$ for $30 \mathrm{~min}$. After nuclease treatment, this step removed the histones (basic proteins) and other proteins that tend to remain associated with the scaffold even after extensive digestion of the DNA. The scaffold was pelleted by centrifugation.

\section{$D G D$ (diethylene glycol distearate) embeddment embeddment free sections}

Embeddment free sections were prepared as described by Capco et al. [17]. Extracted Crypthecodinium cohnii cells or chromosomes were fixed in $2.5 \%$ glutaraldehyde in CSK buffer for $30 \mathrm{~min}$ at $4{ }^{\circ} \mathrm{C}$ and postfixed with $1 \% \mathrm{OsO}_{4}$ in PBS for $30 \mathrm{~min}$ at $4^{\circ} \mathrm{C}$. The cells were dehydrated through a series of increasing ethanol concentration ending with three changes of $100 \%$ ethanol for $10 \mathrm{~min}$ each. Subsequently, the cells were immersed in a mixture of $\mathrm{n}$ butyl alcohol(n BA)/ethanol of $1: 2$ and then $2: 1$, followed by four changes of nBA for 15 min each. The cells were transferred from 100\% $\mathrm{n}$ BA to DGD (Polyscienees inc. ) through a series of nBA/DGD mixture of $2: 1$ arid then $1: 2$, at $60^{\circ} \mathrm{C}, 10 \mathrm{~min}$ each, followed by three changes of $100 \%$ DGD for $1 \mathrm{~h}$ each. DGD were then cooled at $20^{\circ} \mathrm{C}$ to allow the wax to harden. After sectioning, the DGD was removed by immersing the grids into $100 \% \mathrm{n} \mathrm{BA}$ at $20^{\circ} \mathrm{C}$. The grids were returned to $100 \%$ ethanol through a graded series of transitional solvent ethanol mixtures, washed three times in $100 \%$ ethanol, and then dried through the $\mathrm{CO}_{2}$ critical point. Sections were examined in a JEM $100 \mathrm{CX}$ electron microscope at $80 \mathrm{kV}$. 
Nuclear matrix and chromosome scaffold in dinoflagellate

\section{Preparation of whole mounts}

The nuclei of C. cohnii were separated beforehand[ 1 ], extracted as described in section on cell fractionation and dropped onto the grids coated with polylysine. The samples were dehydrated through a graded series of ethanol and dried through the $\mathrm{CO}_{2}$ critical point.

\section{Electrophoresis and immunoblot}

SDS -PAGE was run according to the procedure described by Laemmli[31]. Two dimensional gel electrophoreses were performed essentially following the method of O'Farrell[32]. Silver staining was done by the method of Wary et al. [33]. The reaction of antibodies to protein hands was visualized by the immunoblotting technique of Towbin et al. [34]on nitrocellulose paper. Nitrocellulose strips were incubated in $5 \%$ bovine albumin at $4^{\circ} \mathrm{C}$ for $12 \mathrm{~h}$, rinsed three times in PBS plus 0.05\%(vol/vol) Tween 20, and incubated with anti-lamin antibodies(C23, provided by Dr. Lin, J. J. C. lowa University) [35] at $4^{\circ} \mathrm{C}$ overnight. Excess antibodies were washed with PBS plus Tween 20 . The strips were then incubated with rabbit anti-mouse IgG conjugated to horseradish peroxidase ( $1: 1000$ dilution, Sigma) washed six times in PBS plus Tween 20 for s total of $30 \mathrm{~min}$, then developed in $0.5 \mathrm{mg} / \mathrm{ml}$ diaminobenzidine in $0.01 \%$ ( vol/vol) $\mathrm{H}_{2} \mathrm{O}_{2}$.

\section{RESULTS}

\section{Ultrastructure of the Dinoflagellate nucleus}

The dinoflagellate nucleus contains numerous permanently condensed chromosomes (Fig 1A), whose morphological and biochemical similarities to bacterial nucleoids have attracted, much attention. Permanently condensed chromosomes throughout the cell cycle represent a striking difference from typical eukaryotic chromosomes, the latter are condensed only during nuclear division. At the ultrastructural level, dinoflagellate chromosomes appear as banded structures and each band is composed of both granular and fibrous elements (Fig 1B). The nucleoplasm, enclosed by a double membrane, contains large amount of amorphous matrix and some fibrillar lattice, which suggest the existence of nuclear matrix or nucleoskeleton as proposed earlier [8, 19]. However, this structure does not correspond to the usual definition of nuclear matrix [12 - 18,36]. Here, we use the term nuclear matrix to refer to the isolated, purified, nonchromatin nuclear structure.

\section{Visualization of the nuclear matrix}

After extraction and treatment with Triton X -100, RSB - Magik buffer, DNase I and $0,25 \mathrm{M}$ ammonium sulfate, chromatin was removed from $C$. cohnii nucleus. Then, the samples were fixed, processed to DGD, sectioned, and embedding medium was removed by immersing grids in n-BA. Resinless section electron microscopy revealed a wealth of nuclear substructure obscured in conventionally embedded sections. The resinless section (Fig 2)showed the nuclear interior to be filled with an anatomizing network of fine filaments. The diameter of the nuclear matrix monofiber was about $5 \mathrm{~nm}$ and lots of 15-20nm RNP particles associated with the fiber. The embeddment - free section of an postmitotic cell was shown in Fig 3, with two daughter cells still located in the same cyst. There also existed delicate nuclear matrix in the daughter nuclei. Removing the nuclear RNA resulted in marked distortion of the nuclear matrix.

The preparation procedure for nuclear matrix described here afforded subfractions of nucleus with distinct compositions. Two dimensional gel electrophoresis showed that 
Cai ST et al.
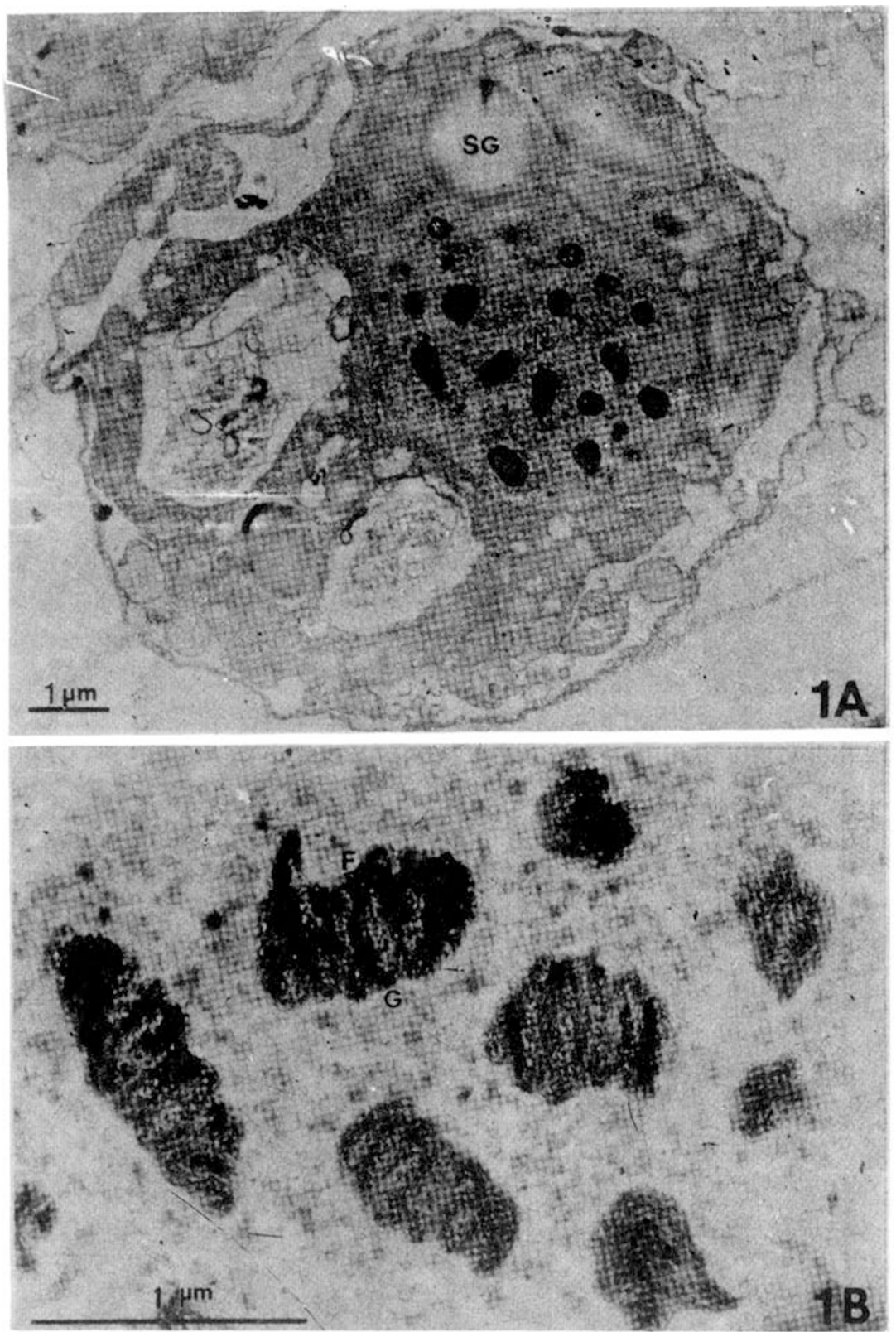

Fig 1. Transmission electron micrographs of Epon 812 embeddment sections of the dinoflagellate Crypthecodinium cohnii. The cell (A) Was surrounded by thin thecal plates. The centrally located nucleus $(\mathbf{N})$ contained numerous banded chromosomes. Many starch grains ( $\mathbf{S G}$ ) may be found throughout the cytoplasm. The permanently condensed chromosomes (B) consisted of a periodic sequence of fibrils $(\mathbf{F})$ and granules $(\mathbf{G})$. There existed matrix structure between chromosomes. 
Nuclear matrix and chromosome scaffold in dinoflagellate

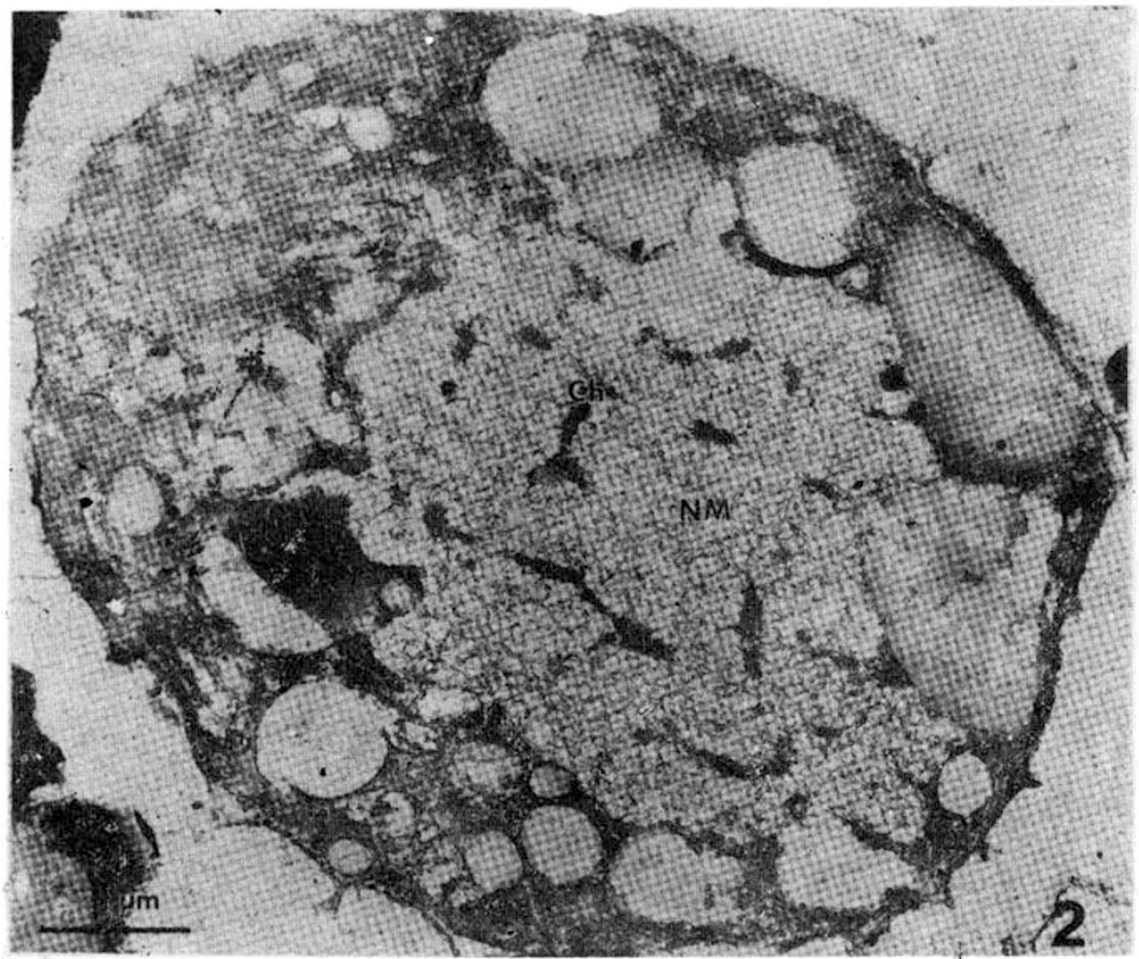

Fig 2. DGD embeddment - free section of an extracted Crypthecodinium cohnii cell. The cells were treated with $0.5 \%$ Triton X - 100, RSB - Magik buffer, followed by DNase I digestion and 0. $25 \mathrm{M}$ ammonium sulfate extraction as described in Materials and Methods. A delicate nuclear matrix (NM) filament network was revealed in the nucleus. The chromosome residues (Ch) were connected by the nuclear matrix filaments.

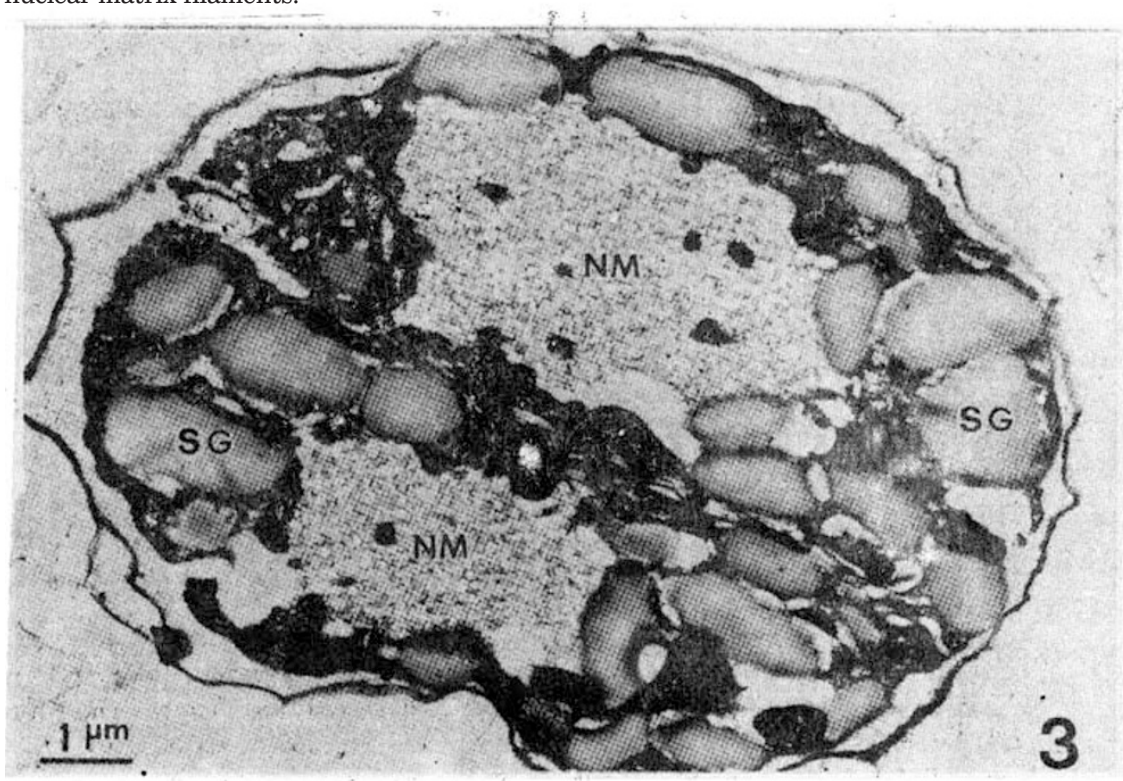

Fig 3. DGD embeddment-free section of a postmitotic cell showing the nuclear matrix scaffolds in daughter nuclei. 
the nuclear matrix was mainly composed of acidic proteins. There existed no basic proteins or histones in the nuclear matrix fraction. (Fig 4).

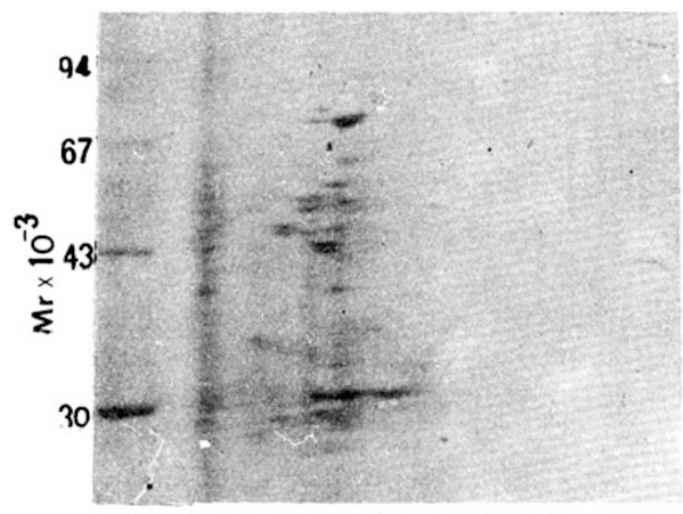

Fig 4. Two-dimensional gel electrophoresis of proteins from isolated dinoflagellate nuclear matrix. The $\mathrm{pH}$ gradient ranged from approximately 3.0 (left side) to 9.0 (right side). Most of proteins in nuclear matrix fraction were acidic protein.

The preparation of cell whole mount preserved overall nuclear morphology and revealed a three dimensional nuclear matrix filament network in the nucleus of the dinoflagellate (Fig 5A). To our surprise, the nuclear lamina was not obvious either on resin section (Fig 1) or resinless sections (Fig 2-3). After sequential extraction, there existed no obvious unbroken boundary between nucleoplasm and cytoplasm and the contour of nucleus was mainly maintained by interior nuclear matrix. In some area of nuclear periphery, fragmentary electron dense bundle were shown (Fig 2), but they were different from the nuclear lamina in higher eukaryotes. In sections using Epon 812 as embedding material the inner nuclear membrane of $C$. cohnii was found to be much thinner than that in mammalian cells, e.g. HeLa cells, which also suggested the deficiency of the nuclear lamina. Therefore at ultrastructural level, nuclear lamina was, at least, undeveloped in the nucleus of dinoflagellate C. cohnii. Immunoblotting analysis showed that mammalian lamin antibodies did not crossreact with $C$. cohnii total proteins (Fig 7 c).

In most of the preparations after DNase I digestion and 0. $25 M$ ammonium sulfate extraction ,chromosomes did not disappear completely. However, they retained large or small amount of chromosome residues (Fig 2). The whole mount micrograph (Fig 5 B) showed dense clusters of filaments in the nuclear matrix scaffold. These filament clusters were in correspondence to the chromosome residues in resinless sections. Fig 6 was a thick section $(\geq 0.2 \mathrm{gm})$ of a mitotic cell. Cytoplasmic channels could be observed on the section. The nucleus was filled with nuclear matrix filaments and chromosome residues. They combined together to form a three dimensional framework in mitotic nucleus. Noticeably, chromosome residues consisted of dense filament bundles, which were more clear in the mitotic cell than those in interphase cells. Considering that the chromosomes of the dinoflagellate are highly condensed, higher concentration of DNase I was used for digestion and most of DNA was removed, but chromosome residues still retained. After depletion of DNA and most of proteins in the chromosome, such a insoluble proteinaceous filament bundles might represent a kind of chromosome scaffold as proposed by some authors [30]. 
Nuclear matrix and chromosome scaffold in dinoflagellate
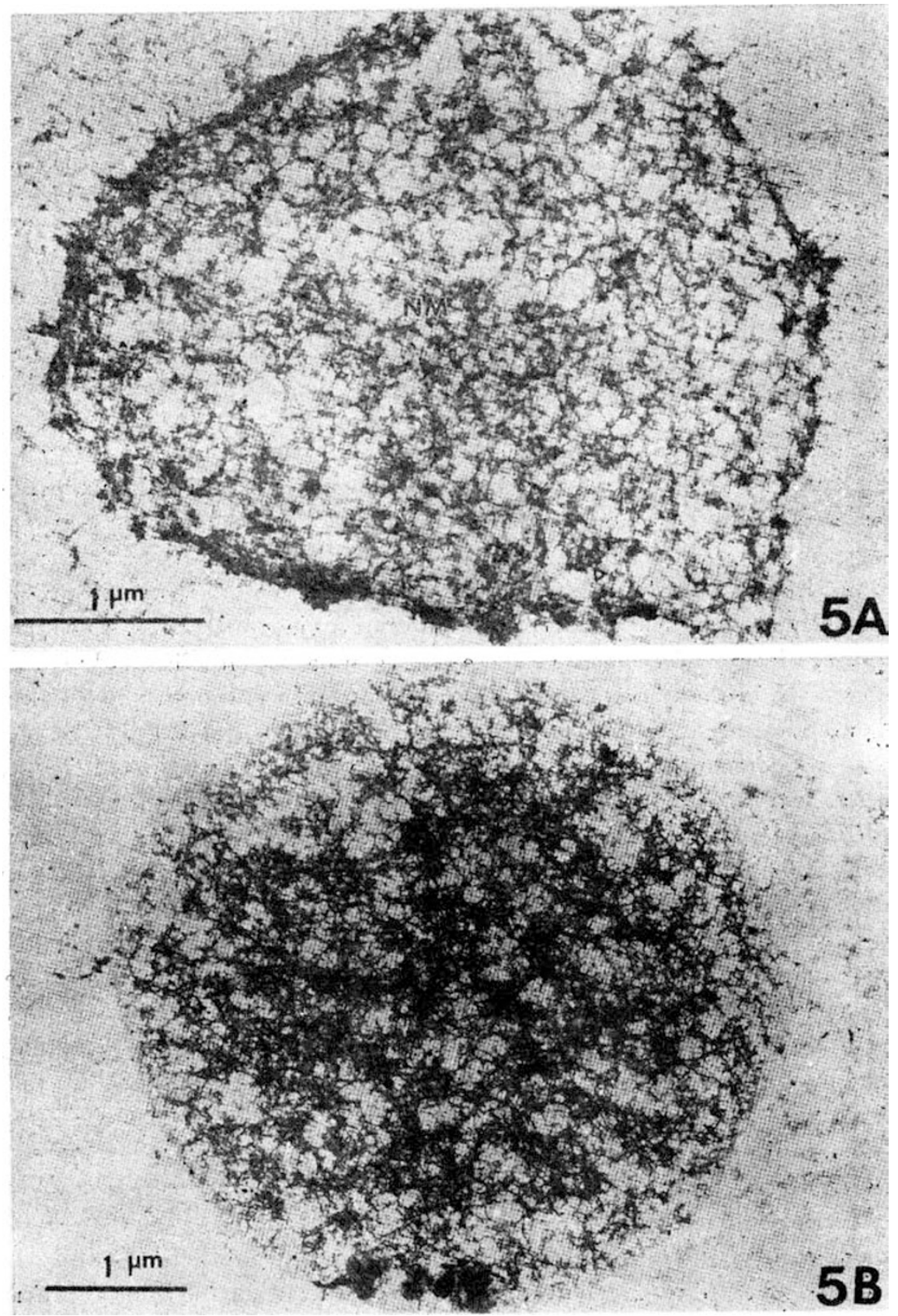

Fig 5. Whole mount transmission electron micrographs of nuclear matrix scaffold of $C$. cohnii. The samples were prepared as described in Material and Methods and viewed as whole mounts. After depletion of chromatin, a delicate network was revealed in C. cohnii nucleus (A), and dense filament cluster can also be visualized on whole mount micrograph (B). 
Cai ST et al.

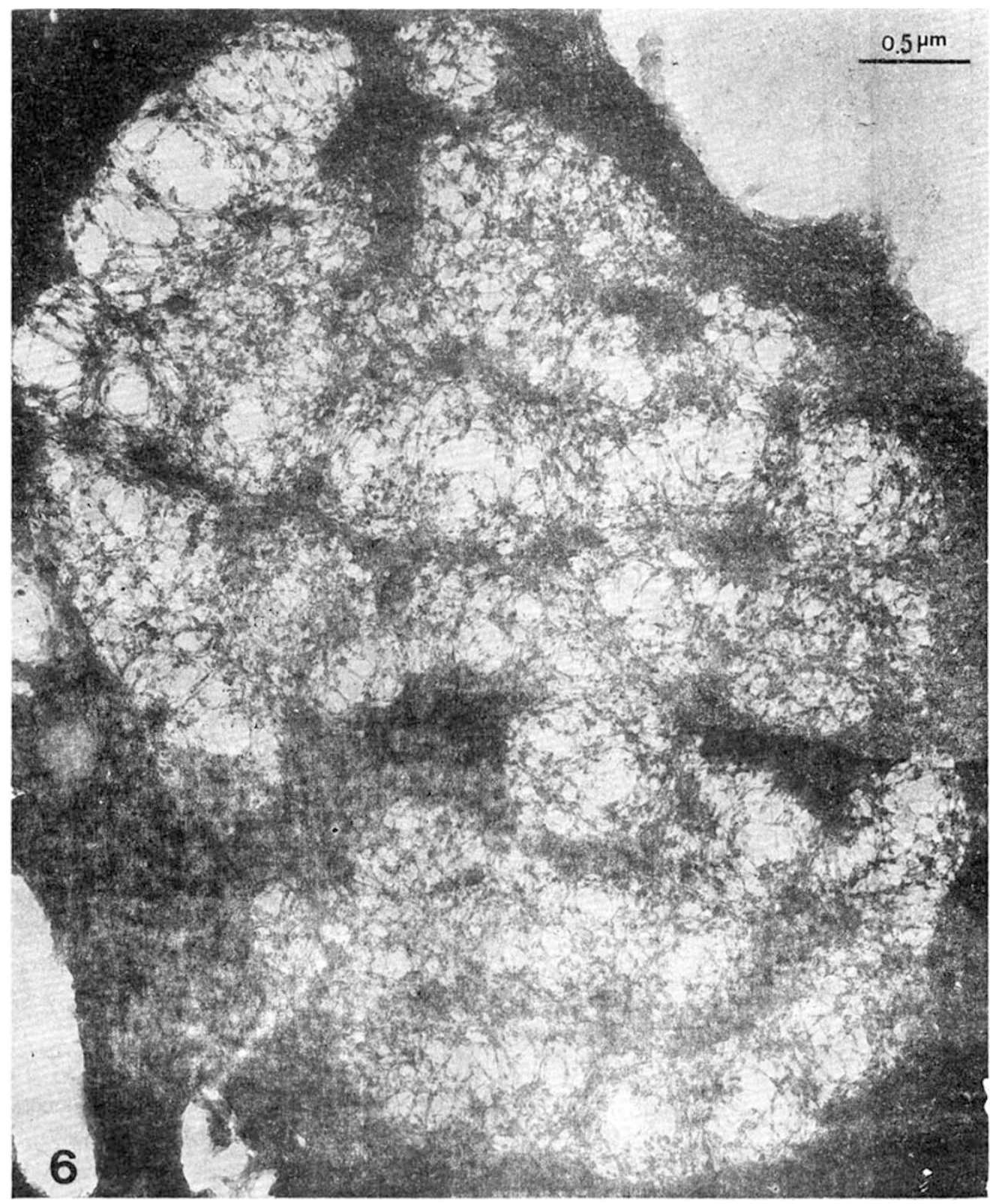

Fig 6. DGD embeddment - free section of a mitotic cell displaying a three dimensional framework in the nucleus. The dense filament bundles were also revealed in chromosome area. 
Nuclear matrix and chromosome scaffold in dinoflagellate

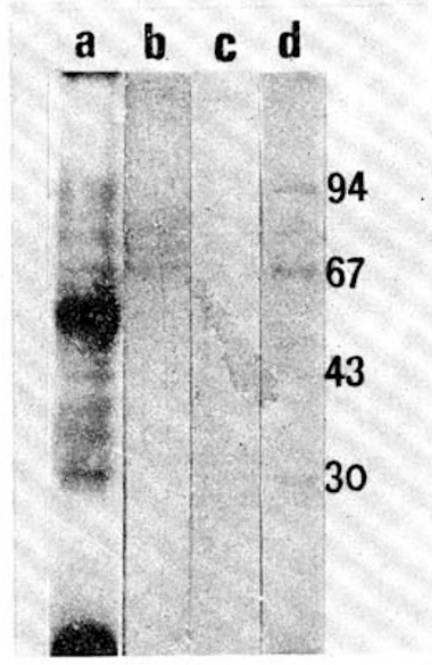

Fig 7. SDS- PAGE and immunoblotting analysis of proteins from C. cohnii. (a) Electropherogram showing the nuclear matrix proteins. $(\mathbf{b}-\mathbf{c})$ immunoblot analysis of total proteins showing that lamin antibody (C23), which react with lamin polypeptides of HeLa cell (b), did not crossreact with $C$. cohnii total proteins (c). (d) molecular weight marker.

\section{Visualization of the chromosome scaffold}

The above results suggested the existence of chromosome scaffolds in the primitive chromosomes of dinoflagellate. In order to visualize the chromosome scaffold directly, the isolated chromosomes (Fig 8) were digested with DNase I and extracted with dextran sulfate and heparin, then processed to DGD embeddment-embeddment free sections. We revealed a delicate filament network in the chromosome of C. cohnii. The scaffold was resistant to the treatment of DNase I or $2 M \mathrm{NaCl}$, however, it was sensitive to the treatment of $4 M$ urea or proteinase $\mathrm{K}$. Two dimensional electrophoresis showed that the chromosome scaffold consisted of acidic proteins (Fig 9).

DGD embeddment-embeddment free section method was used, for the first time, in chromosome scaffold ultrastructure study and showed some advantages in revealing of inner substructure of the chromosome scaffold. Fig 10-11 showed the morphology of chromosome scaffolds in different sections. After depletion of DNA and soluble proteins, the acidic protein scaffolds retained the shape and size of the chromosomes. On

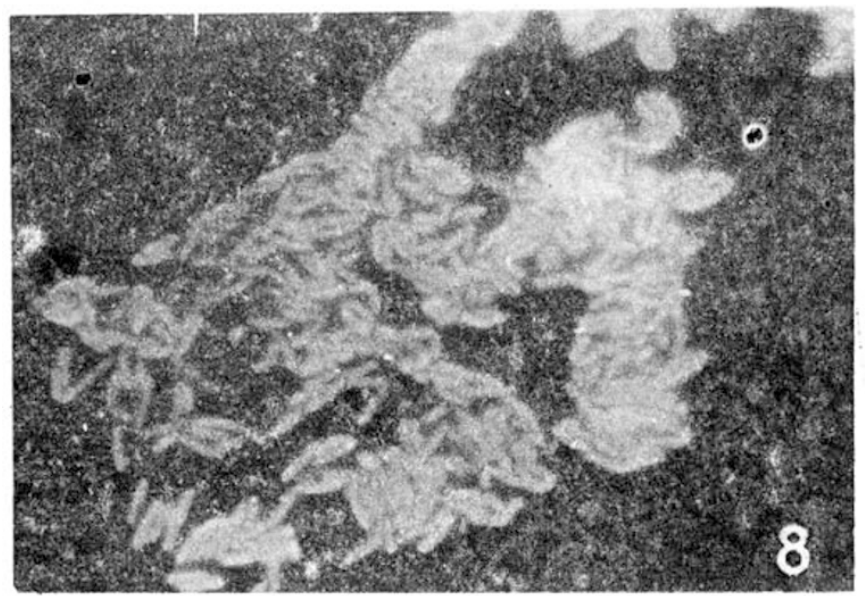

Fig 8. Fluorescence micrograph showing the isolated C. cohnii chromosomes stained with DNA fluorescent dye DAPI. 
Cai ST et al.

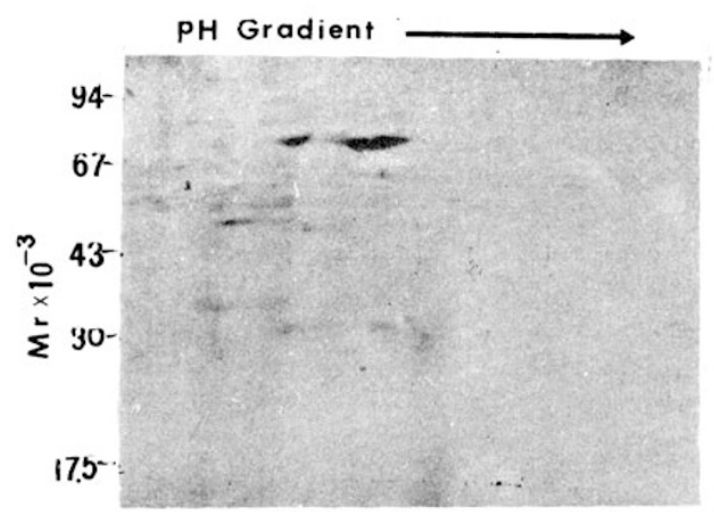

Fig 9. Two-dimensional gel electrophoresis of proteins from isolated dinoflagellate chromosome scaffold. The $\mathrm{pH}$ gradient ranged from approximately 3.0 (left side) to 9.0 (right side). Most of proteins of chromosome scaffold were acidic protein.

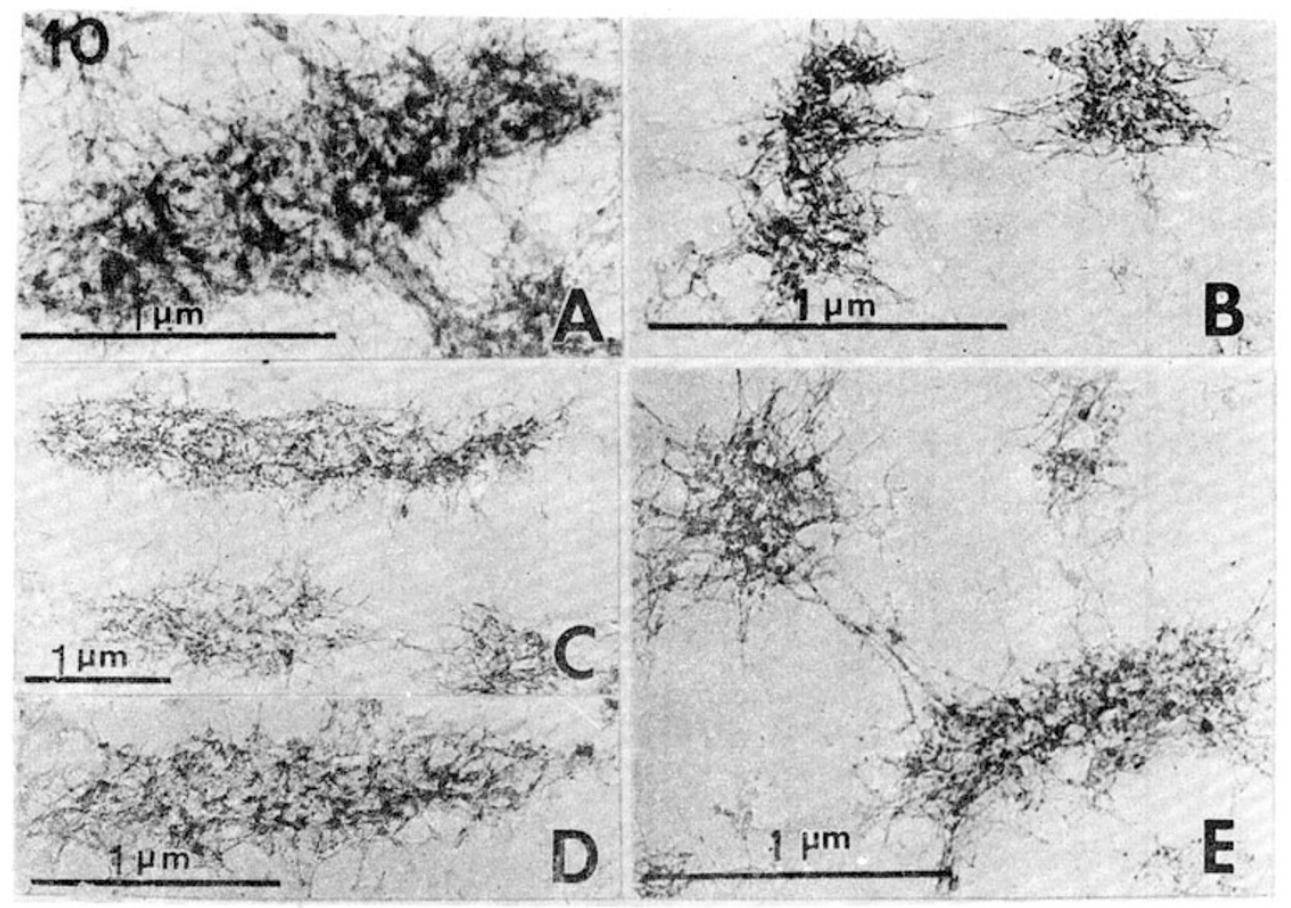

Fig 10. DGD embeddment-free sections of the dinoflagellate chromosome scaffolds. The protein scaffolds retain the characteristic shape of the chromosomes.

thick section $(\geq 0.2 \mu \mathrm{m})$, the chromosome scaffold displayed a dense filament bundle structure and the band of the chromosome were visible on the chromosome scaffold (Fig 10A). The results demonstrated that the isolated chromosome scaffold strikingly corre sponded with the characteristic morphology of the dinoflagellate chromosome. On thin sections $(500-700 \AA)$, delicate filament networks were revealed in the chromosomes (Fig $10 \mathrm{~B}-\mathrm{E}$ ). No filament dense aggregates at the core or the axis of the chromosomes were found either on cross sections or longitudinal sections. We believe that chromosome scaffold is not an axis or core scaffold as supposed by some chromosome models $[25,30]$, but a network spreading over the whole chromosome. On some 
Nuclear matrix and chromosome scaffold in dinoflagellate
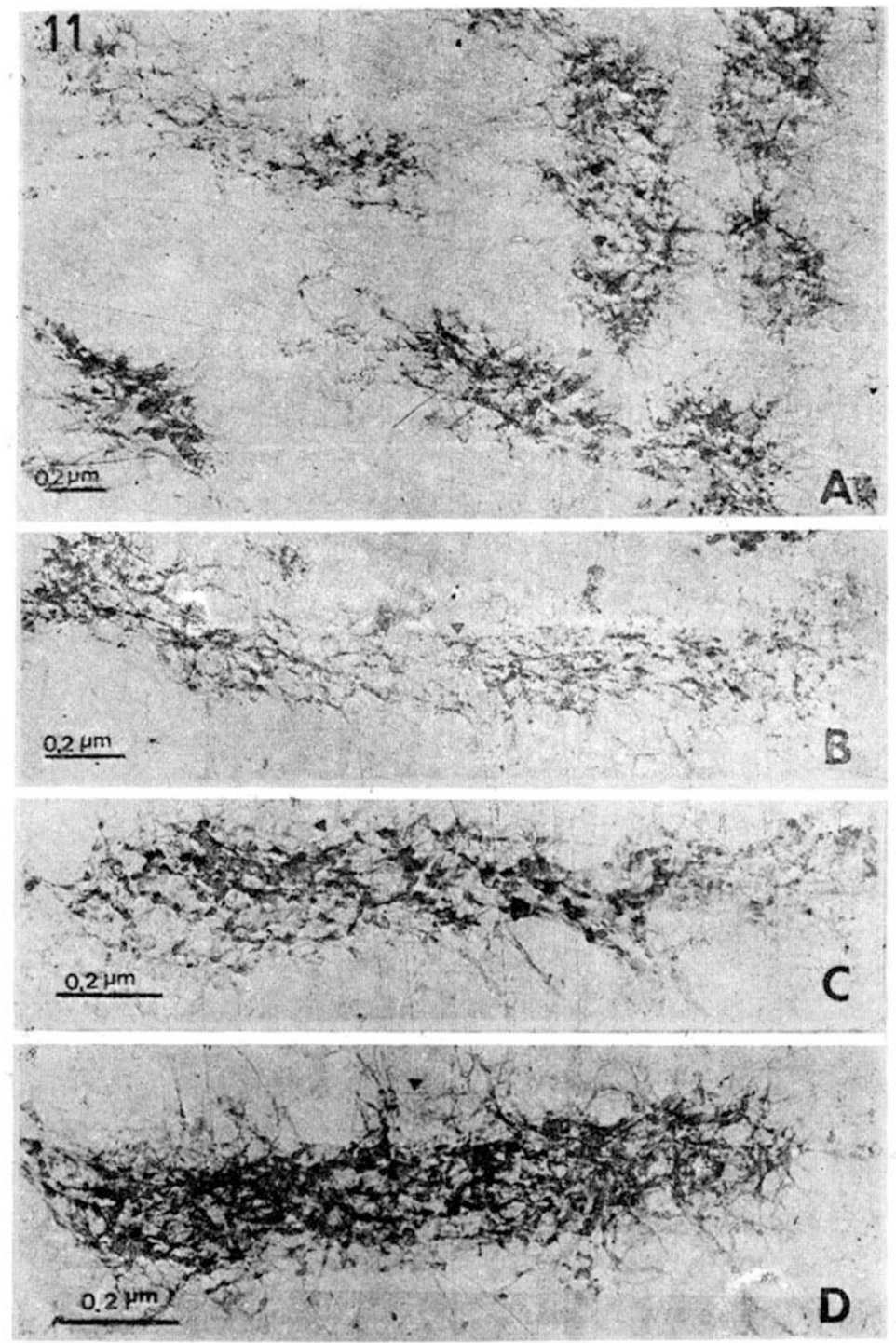

Fig 11. High magnification of the chromosome scaffolds. The monofiber can be visualized clearly on DGD embeddment-free sections and the diameter of the scaffold filament is about $10 \mathrm{~nm}$. 
ultrathin sections (Fig 10B, C, E) a few filaments radiated from the chromosome scaffold and some filament association between chromosomes were be observed. The significance of these filaments and their relation to the nuclear matrix scaffold remain to be seen.

The monofiber of the chromosome scaffold could be visualized clearly in high magnification electron micrographs (Fig 11 A D). The diameter of the chromosome scaffold filament was about $10 \mathrm{~nm}$, which is much thicker than the naked DNA fiber (2 3 $\mathrm{nm}$ ) in dinoflagellate chromosome [24]. In some area of the chromosome a delicate filament network was revealed clearly (Fig 11 A B).

\section{DISCUSSION}

\section{The advantages of resinless sections in the study of the nuclear matrix and chromo- some scaffold}

The first question should be mentioned here is DGD embeddment embeddment free section electron microscopy techniques. In conventional section techniques, embedding resin and biological structures scatter electrons in nearly similar way so that the latter are almost invisible. Images are actually formed by heavy metal stains at the section surface. Embeddment free techniques dispense with embedding resin and images are formed directly by biological structure in vacuum. It can image the nuclear interior structure powerfully as described by Capco et al. [17]. A major technical innovation in this paper is the application of the resinless section technique on the chromosome scaffold research. Compared with other techniques in chromosome scaffold ultrastructure studies [37], the embeddment free section used here reveals more structural information of the chromosome protein scaffold, and many micrographs presented in this paper also show, for the first time, a delicate nuclear matrix in the nucleus of $C$. cohnii.

\section{There existed nuclear matrix in the nucleus of dinoflagellate Crypthecodinium cohnii}

Much attention has been focused on the dinoflagellate nucleus as there are many unusual features that characterize it. Despite some similarities to classic eukaryotes, dinoflagellate contains no obviously histone like protein and nucleosome [1,2]. The basic protein DNA ratios range from 0.08 to 0.13 , while these ratios are generally greater than one in most eukaryotes. The ratio of DNA to acidic protein was found to be approximately one, which is comparable to that found in purified eukaryotic nuclei [38]. In correspondence to these facts, the DNA of dinoflagellate is not organized into chromatin structure but arranged in highly coiled bundles [8, 29], similar in general appearance to that in the prokaryotic pronucleus. Meanwhile, non-histone protein nuclear matrix filament network is evident throughout the cell cycle as shown in our experiments. It is a continuous structure that extends all over the nucleoplasm and retains the spatial disposition of the nucleus after the removal of phospholipid, nucleic acid and most of cellular proteins. The morphology and some physical properties of nuclear matrix are similar to those in higher eukaryotes. The maintenance of nuclear contour and chromosome association suggests that the nuclear matrix plays an important role in the organization of the nucleus. Although the nuclear matrix was postulated to be a scaffold 
Nuclear matrix and chromosome scaffold in dinoflagellate

in the nucleus of eukaryote [19], the direct evidence supporting the hypothesis has so far been yet insufficient. The demonstration of the presence of nuclear matrix in the dinoflagellate may be a good example in this regard.

Whether or not nuclear lamina appeared in the primitive eukaryote dinoflagellates has not been clarified yet. The nuclear lamina is a polymeric protein meshwork that lines the nucleoplasmic surface of the nuclear envelope [39]. Immunocytochemical studies indicated that the lamina is present in nearly all interphase nuclei, at least, in higher eukaryotes [40]. As a relatively insoluble structure, the lamina is commonly present in residual nuclear matrix fraction. Some reports mentioned that the nuclear lamina was more stable than the interior nuclear matrix in resisting the non-ionic detergent and high salt extraction [16, 41]. The preparation procedure used in this paper can preserve the nuclear lamina very well and its morphology could be visualized clearly in higher eukaryotes [17, 18, 36, 42, 43]. Nevertheless, the same method could not reveal nuclear lamina-like structure in dinoflagellate nucleus (Fig 2). Our results indicated that there is no well developed nuclear lamina structure between nucleoplasm and cytoplasm in dinoflagellate C. cohnii, and that the mammalian anti-lamin antibodies does not crossreact with $C$. cohnii total proteins. However, any definite conclusion about the deficiency of nuclear lamina in dinoflagellate could not be reached without further data. The nuclear lamina is postulated to provide an architectural framework for the nuclear renvelope and an anchoring site at nuclear periphery for interphase chromosomes. It is involved in nuclear envelope disassembly and reassembly during mitosis [44], and chromosome decondensation after division [45]. Inhibition of lamina assembly leads to abnormal assembly of nucleus $[45,46]$. We postulated that some of the primitive characteristics of dinoflagellate nucleus, such as unusual mitosis and chromosome behavior, may partly be related to the lack of nuclear lamina. In other words, whether nuclear lamina functioned in the evolution from primitive eukaryote to typical eukaryote is a quite interesting subject.

\section{There existed protein scaffold in the chromosome of dinoflagellate Crypthecodinium cohnii}

What interested us is that after DNase I digestion and salt elution, the dinoflagellate chromosomes did not disappear completely. They retained some salt insoluble protein residues. Several dinoflagellate chromosome models [25, 30] hypothesized that some kind of backbone or protein scaffold might function in maintaining the chromosome structure. We proposed that such a chromosome residue may actually represent chromosome scaffold. To testify this hypothesis, it is necessary to isolate and visualize the chromosome scaffold directly.

Our results showed, for the first time, that there existed really a delicate acidic protein filament network in the primitive chromosome of the dinoflagellate, which was quite beyond our expectation. The chromosome scaffold preserved the characteristic morphology of the chromosome. Most of the models proposed for the dinoflagellate chromosome only considered the organization of DNA fiber and neglected the large amounts of acidic proteins in the chromosome [9,27-29,47]. In our opinion, the highly coiled DNA needs some mechanism to stabilize the superstructure, and the acidic pro- 
tein may fulfill this function.

\section{Relation between the nuclear matrix and chromosome scaffold}

The next question is the relation between nuclear matrix and chromosome scaffold. Extensive investigation have been carried out on the interphase nuclear matrix [12-18] and mitotic chromosome scaffold [20-23, 37] in higher eukaryotes. Although several studies showed some similarities between these structures and suggested that interphase nuclear matrix might be involved in mitotic chromosome construction [48-51]. However, the detailed knowledge of this relation is scarce. The dinoflagellates are good models for studying the association of nuclear matrix and chromosome scaffold. One of the primitive feature of dinoflagellates is the presence of permanently condensed chromosomes throughout the life cycle. Moreover, the nuclear envelope remain intact during mitosis. Chromosomes and extra-chromosome nucleoplasm co-exist in the same nucleus. Investigation on dinoflagellate will provide information on the structural and biochemical relation between nuclear matrix and chromosome scaffold. The micrographs presented here showed that,in either mitotic or interphase cells, chromosome residues and nuclear matrix filaments integrated together to form a complete framework spreading all over the nucleoplasm. In some area of the nuclear space, it was indistinguishable between chromosome scaffold filaments and nuclear matrix filaments. Further morphological and biochemical data will aid in understanding the maintenance of the highly ordered structure of the nucleus.

\section{Nuclear matrix and chromosome scaffold in evolution}

The emergence of eukaryote is an important event in evolution. The investigation on the origin and evolution of nuclear envelope and chromatin has been reported elsewhere [52-54]. However, the evolution of nuclear matrix and chromosome scaffold has rarely been illustrated yet. We use one of the primitive eukaryote dinoflagellate as an experimental model to investigate the nuclear matrix and chromosome scaffold in eukaryote evolution. Our results demonstrated that the nuclear matrix and chromosome scaffold is present in such a primitive nucleus. Since dinoflagellate first appeared on the earth in remote antiquity, it is suggested that the nuclear matrix and chromosome scaffold might have preceded the evolution of chromatin in the cell nucleus. This is significant as it indicated that acidic protein (nonhistone protein) nuclear matrix and chromosome scaffold might be involved in chromatin evolution. Berezney [19] postulated earlier that chromatin might have evolved special properties enabling to effectively interact with the pre-existing matrix structure. The detailed knowledge of the interaction of chromatin with nuclear matrix and chromosome scaffold in the primitive eukaryotes may shed light on the organization and evolution of eukaryotic nucleus.

In summary, our experiments demonstrated that the nuclear matrix and chromosome scaffold had come into existence in one of the primitive eukaryotes, dinoflagellate Crypthecodinium cohnii. The results suggested that nuclear matrix and chromosome scaffold might emerge very early in evolution and might be involved in chromatin evolution. We believe that the nuclear matrix and chromosome scaffold are essential components of the eukaryote nucleus and exist universally in eukaryotic cells. 


\section{Nuclear matrix and chromosome scaffold in dinoflagellate}

\section{REFERENCES}

[1] Rizzo PJ, and Noodén LD. Isolation and partial characterization of dinoflagellate chromatin. Biochem Biophys Acta 1974a; 349:402 14

[2] Rizzo PJ, and Noodén LD, Partial characterization of dinoflagellate chromosomal proteins. Biochem Biophys Acta 1974b; 349: 41527.

[ 3 ] Bodanskey S, Mintz LB, and Holmes DS. The mesokaryote Gyrodinium cohnii lacks nucleosomes. Biochem Biophys Commun 1979; 88:1329 36.

[4] Rizzo PJ, and Burghardt RC. Histone like protein and chromatin structure in the wall less dinoflagellate Gymnodinium nelsoni. Biosystems 1982; 15:27 34 .

[5] Rae PMM. 5 Hydroxymethyluracil in the DNA of a dinoflagellate. Proc Natl Acad Sci USA 1973; 70:1141 5.

[6 ] Rae PMM. Hydroxymethluracil in eukaryote DNA: a natural feature of the Pyrrhophyta (Dinoflagellates). Science 1976; 194:1062 4.

[ 7 ] Leadbeater B, and Dodge JD, Fine structure of the mitotic chromosome scaffolds. J Cell Biol 1985; 100:1706 15 .

[ 8 ] Kubai DF, and Ris H. Division in the dinoflagellate Gyrodinium cohnii (Schiller). A new type of nuclear reproduction. J Cell Biol 1969;40:508 28.

[9] Oakley BR, and Dodge JD. Evidence for a double helically coiled toroidal chromonema in the dinoflagellate chromosome. Chromosoma 1979;70:277 91.

[10] Spector DL, and Triemer RE. Chromosome structure and mitosis in the dinoflagellates: an ultrastructural approach to an evolutionary problem. Biosystems 1981; 14:289 98.

[11] Dodge JD. Chromosome structure in the dinoflagellates and problem of the mesokaryotic cell. Int Cong Ser Excerpta Med 1965; 91:264 5 .

[12] Berezney R, and Coffey DS,Identification of a nuclear protein matrix. Biochem. Biophys Res Commun. 1974; 60:1410 17 .

[13] Comings DE, and Okada TA, Nuclear protein III: the fibrillar nature of the nuclear matrix. Exp Cell Res 1976; 103:341 60 .

[14] Hodge LD, Mancini P, Davis FM, and Heywood P. Nuclear matrix of Heta cells. J Cell Biol 1977; 72:192 208.

[15] Long BH, Huang CY, and Pogo AO. Isolation and characterization of the nuclear matrix in Friend erytheoleukemia cells: chromatin and hnRNA interactions with the nuclear matrix. Cell 1979; 18:1079 90.

[16] Kaufmann SH, Coffey DS, and Shaper JH. Consideration in the isolation of the rat liver nuclear matrix, nuclear envelope and pore complex lamina. Exp Cell Res 1981; 132:105 24.

[17] Capco DG, Krochmalnic G, and Penman S. A new method for preparing embeddment free section for TEM: application to the cytoskeletal framework and other three dimensional network. J Cell Biol 1984; 98:1978 85 .

[18] Fey EG, Krochmalnic G, and Penman S. The nonchromatin matrix of nucleus: protein and RNA components revealed by Sequential fractionation and resinless TEM section. J Cell Biol 1986; 102:1645 65.

[19] Berezney R. Organization and function of the nuclear matrix. In: Hnilica L S. ed. ChromosomaI Nonhistone Proteins. Vol. IV. , CRC Press 1984:119 73.

[20] Adolph KW, Cheng SM, and Laemmli UK. Role of nonhistone protein in metaphase chromosome structure. Cell 1977:12:805 6.

[21] Paulson JR, and Laemmli UK. The structure of histone depleted metaphase chromosome. Cell 1977; $12: 817$ 28.

[22] Laemmli UK. Cheng SM, Adolph KW, Paulson JR, Brown JA, and Baumbach WR, Metaphase chromosome structure: the role of non histone proteins. Cold Spring Harbor Symp Quant Biol 1978; 42:351 60.

[23] Adolph KW, Cheng SM, Paulson JR, and Laemmli UK. Isolation of protein scaffold from mitotic HeLa cell chromosomes. Proc. Natl Acad Sci USA 1977;74:4937 40.

[24] Ris H, Interpretation of ultrastructure in the cell nucleus. In: Harris, R. J. C. , ed. The Interpretation of Ultrastructure. Academic Press. NewYork,1962: pp69 88.

[25] Giesbrecht PM, Uber das ordungsprinzip in der chromosomen von dinoflagellaten und Bakterien. Zentrabl. Baketeriol., Parasitenkd., Infecktionskr. Hyg., Abt. 1: Orig 1965; 196:510 19.

[26] Grassé RP, Hollande A, Cachon J, and Cachon Enjumet M. Interpretation de quelques aspects infrastructuraux des chromosomes de péridiniens en division. C. R. kebd. Seances Acad Sci 1965; 260: 6975 78:

[27] Bouligand Y, Soyer MO, and Puiseux Dao S, La structure fibrillaire et l'orientation des chromosomes chez 
les dinoflagellates. Chromosoma 1968; 24:251 87.

[28] Haapala OK, and Soyer MO. Structure of dinoflagellate chromosomes. Nature (Lond.) 1973;244:195 7.

[29] Livolant F, and Bouligand Y, Double helical arrangement of spread dinoflagellate chromosomes. Chromosoma. 1980;80:97 118.

[30] Spector DL, Pfiester LA, and Triemer RE, DNA duplication and chromosome structure in dinoflagellates. Protoplasma 1981;105:185 94.

[31] Laemmli UK. Cleavage of structural proteins during the assembly of the head of bacteriophage T4. Nature (Lond). 1970;227:680 5.

[32] O'Farrell PH, High resolution two dimensional electrophoresis of proteins. J Biol Chem 1975;250:4007 21.

[33] Wary W, Bowlikas T, Wary VP, and Hancock R. Silver staining of proteins in polyacrylamide gels. J Anat Biochem1981;118:197 203.

[34] Towbin H, Staehelin T, and Gordon J. Electrophoretic transfer of proteins from polyacrylamide gels to nitrocellulose sheets:procedure and some application. Proc Natl Acad Sci USA 1979;76:4350 4.

[35] Lin JJC, Lin JLC, Davis Nathaumar EJ, and Lourim D. Monoclonal antibodies against caldesmon, a $\mathrm{Ca}_{2}+/$ calmodulin and actin binding protein of smooth muscle and nonmuscle cells. Hybridoma 1988;7:273 88.

[36] Zhai ZH, Nikerson JA, Krochmalnic G, and Penman S. Alternation in nuclear matrix structure after adenovirus infection. J Virology 1987;61:1007 18.

[37] Paulson JR, Scaffolding and radial loops: the structural organization of metaphase chromosomes. In:Adolph, K. W. ed. Chromosomes and Chromatin Academic Press, New York, 1988;pp3 36.

[38] Rizzo PJ. Comparative aspects of basic chromatin proteins in dinoflagellates. Biosystems 1981;14:433 43.

[39] Gerace L, Blum A, and Blobel G. Immunochemical localization of the major polypeptides of the nuclear pore complex lamina fraction: interphase and mitotic distribution. J Cell Biol 1978; 79:546 66.

[40] Krohne G, and Benavente R. The nuclear lamins: A multigene family of proteins in evolution and differentiation. Exp Cell Res 1986;162:1 10.

[41] Kaufmann SH, Gibson W, and Shaper J. Characterization of the major peptides of the rat liver nuclear envelope. J Biol Chem 1983;258:2710 1.

[42] Zhai ZH, Wang X, and Qian XY, Nuclear matrix intermediate filaments system and its alteration in adenovirus infected HeLa cell. Cell Biol Int Reports 1988;12:99 108.

[43] Jiao RJ, Wu DL,Zhang B, Cai ST, and Zhai ZH. Immunogold labelling the intermediate filament lamina nuclear matrix system in HeLa cells and BHK 21 cells. JEMT 1991;18:126 34.

[44] Gerace L, and Blobel G. The nuclear envelope lamina is reversibly depolymerized during mitosis. Cell 1980; 19:277 87 .

[45] Benavente R, and Krohne G. Involvement of nuclear lamins in postmitotic reorganization of chromatin as demonstrated by microinjection of lamin antibodies. J Cell Biol 1986;103:1847 54.

[46] Burke B, and Gerace L. A cell free system to study reassembly of the nuclear envelope at the end of mitosis. Cell 1986;44:639 52 .

[47] Rill RL, Livolant F, Aldrich HC, and Davidson MW, Electron microscopy of liquid crystalline DNA: direct evidence for cholesteric like organization of DNA in dinoflagellate chromosomes. Chromosoma 1989; 98:280 6.

[48] Lewis CD, Lebkowski JS, Daly AK, and Laemmli UK, Interphase nuclear matrix and metaphase scaffolding structure. J Cell Sci 1984;suppl. 1:103 22.

[49] Mirkovitch J, Mirault M E, and Laemmli UK. Organization of the higher order chromatin loop: specific DNA attachment sites on nuclear scaffold. Cell 1984;39:223 32.

[50] Pienta KJ, and Coffey DS, A structural analysis of the role of the nuclear matrix and DNA loops in the organization of the nucleus and chromosome. J Cell Sci 1983; suppl. 1:123 35.

[51] Earnshaw WC, Halligan B, Cooke CA, Heck MMS, and Liu LF. Topoisomerase II is a structural component of dinoflagellate transverse flagellum. Nature (Lond.) 1967;213:421 2.

[52] Kimura M. The Neutral theory of molecular evolution. Cambridge University Press. 1984.

[53] Gualerz CO, Pon CL. Bacterial chromatin. Spering Verlag. 1986.

[54] Adolph KW. Chromosome: Eukaryotic, Prokaryotic and viral. CRC Interscience 1989.

\section{Received 209 1991. Revised 2212 1991. Accepted 1011992}

